\title{
E-Value Strategies in Internet Retailing: The Case of a Malaysian Leading E-Coupon Retailer
}

\author{
Siew Fun Tang ${ }^{1} \&$ Pooi Yang Tong ${ }^{2}$ \\ ${ }^{1}$ Teaching and Educational Development, and Taylor's Business School, Taylor's University, Malaysia \\ ${ }^{2}$ Taylor's Business School, Taylor's University, Malaysia \\ Correspondence: Siew Fun Tang, Teaching and Educational Development, and Taylor's Business School, \\ Taylor's University, Malaysia. Tel: 60-3-5629-5293. E-mail: siewfun.tang@taylors.edu.my
}

Received: June 16, 2013 Accepted: July 9, 2013 Online Published: September 29, 2013

doi:10.5539/ass.v9n13p252

URL: http://dx.doi.org/10.5539/ass.v9n13p252

\begin{abstract}
Internet retailing industry is considered as an infant industry in Malaysia. Although there has been a rising trend, weak e-commerce infrastructure has resulted consumers to perceive online transaction to be unsafe. This study investigated on e-value strategies adopted by a Malaysian leading Internet retailer in order to change consumer's skepticism. The e-value strategies employed by the case company emphasized on value innovation which include flexible organizational structure, open communications, innovative spirit, and people focus and strong work culture. It is evident that the company has benefited from value creation and innovation where sustainable strategic efforts were combined with entrepreneurial knowledge in designing the deal creation process.
\end{abstract}

Keywords: e-value strategies, internet retailer, Malaysia, value creation, value innovation

\section{Introduction}

Internet retailing refers to "the sale of retail goods via online channels, valued at retail selling price" (Datamonitor, 2009). The global Internet retail sector is forecasted to have a value of $\$ 613.3$ billion in 2013; an increase of $88.6 \%$ since 2008 . Globally, Internet retailing is expected to post a $13 \%$ compound annual growth rate (CAGR) over the period of 2010 - 2015. According to Euromonitor (2012a), Malaysia's Internet retail realized RM842 million in 2011 and will expect to post CAGR of 15\% to reach RM1.7 billion in 2016. Despite the growth, Malaysians remain uncomfortable when transacting online due to inadequate retail infrastructure such as thorough distribution networks and secure payment system (Chua et al., 2006; Euromonitor, 2012a). Such frail electronic payment security, weak delivery systems, and low PC penetration affect the level of development of Internet retailing (Euromonitor, 2011). The Malaysian government is actively engaged in advancing telecommunications infrastructure and management, including increasing broadband penetration as well as sustainable mobile Internet coverage nationwide.

Consumers today are prioritizing the aspect of value for money when purchasing goods. This rising trend within the retail industry has fortified the need to understand the e-value strategies that Internet retail companies are using today. E-value strategies are defined as "business re-engineering for e-success" (Reynolds, 2000; Moore \& Ruddle, 2000), "new opportunities for strategic marketing" (Evans \& Wurster, 2000) and "development of successful e-business plans" (Hooft \& Stegwee, 2001).

\subsection{Bargain-Hunting Culture}

The rising trend of "collective buying phenomenon" appeals to the new bargain-hunting culture that has been sparked by the 2008 recession (Euromonitor, 2012b). This new consumer mind-set has accelerated business migration to e-commerce where it plays the role to move stagnant inventory. In this study, the market segment explored is coupon retailing defined as products and services are transacted through online coupon channels. With regards to the 2008 recession, Hempel (2010) states that affected businesses like restaurants, retailers, and suppliers have built up excess inventory due to reduced level of consumer spending. He further adds that the recession had a positive impact on Internet sales. Consumers and some businesses are reducing implicit and explicit costs by resorting to Internet adoption in bricks-and-mortars.

Today, the role of consumers in the purchasing process has shifted from being passive to active in searching for and obtaining coupons (Fortin, 2000). According to Porter (2001), Internet retail offers added value to 
consumers by providing extensive product information and services, which facilitates purchase decisions. With a combination of extensive product information and discounted goods on coupon retail websites, consumers now can enjoy facilitated bargain-hunting. Despite higher consumer reach, Porter (2001) and Huizingh (2002) highlight that Internet also introduces new competitors.

\subsection{Formulating and Communicating E-Value Strategies}

Strategic approaches can be systematically designed according to whether they place content of a strategy or the process is at the center of consideration. Strategy formation is characterized into two broad definitions that are strategy-content research and strategy-process research (Rajagopalan \& Spreitzer, 1996). The essence of strategy-content approach experiments is that strategy will perform successfully under which market environment. The strategy-process approach is portrayed as "a consciously shaped organizational process" which ultimately contributes to added value (Raupp \& Hoffjann, 2012). This approach allows organizations to distinguish the source of its competitive advantage if the value lies within the implementation of the strategy or the design of the specialized business functions.

Formulating strategies is now a continuous and iterative business activity. In order to reach managerial objectives and corporate strategies, employees at all level in the organization must be communicated of the direction and the key performance indicator to be enable a successful contribution to achieving the goal (Tourish \& Hargie, 1996). The conduct of an implicit strategy relies heavily upon the strategy implementation process. Essentially, it is to know what to be achieved, plan how and who to do it, evaluate the progress made and reward or coach positive behaviour. Today, the formulation process that most organic, flat hierarchical companies are adopting is known as functional strategizing. Steyn (2003), Harrison \& St John (1998) and Steinmann \& Schreyögg (2005) define functional strategy as the role of departments to formulate their own "rationalities of action". Process methodologies allow to spawn a higher level of commitment among senior and middle level managers due to their active participation in strategizing which is ideal for most companies today (Thompson, 2000).

The implications of implementing strategies lie in the employee's understanding of direction and action plan, committing to monitoring performance on a day-to-day basis and taking corrective action to recover from changing environments (Whittaker, 1996). Companies should only provide total customer solutions that consumers sees value in. Then only the employee can take credit for the role of delivering added value when strategies have been communicated effectively. E-businesses can refine their online business processes to increase the ease of navigation and interactivity that enhances the overall shopping experience of a coupon customer which is discussed in the later subtopic. A whole new set of value propositions and sources of competitive advantage will be established if e-coupon retailers are able to provide greater security or to increase the quantity of digital deliveries. Besides that, new specialized functions within each department may also be established to ensure that the promise of added value is delivered.

\subsection{Conventional Strategic Logic vs. Value Innovation}

On a broader perspective, the strategies employed by managers will indicate the company's inclination towards either conventional strategic logic known as value creation or value innovation (See Table 1). Value creation is said to be "configuration of the value chain (Porter, 1985), formation of strategic networks among firms (Dyer \& Singh, 1998), or the exploitation of firm specific core competencies (Barney, 1991)". Value innovation, on the other hand, accentuates on delivering the value customers seek and makes competition irrelevant by capitalizing on its new, innovative ways of doing things (Kim \& Mauborgne, 1999). Value innovators seek for what customer's value in common and build their business models around the fundamental dimensions. Conversely, traditional value creators are driven by the idea of "staying ahead of the competition". Kim and Mauborgne (1999) distinguish high-growth companies i.e. value innovators from their competitors in the way they make sense of how they do business.

In a longitudinal five-year study of high-growth companies, Kim and Mauborgne (2004) implied that the way each of these industrial moguls approached strategy makes that quantum leap in added value. They recommend that managers should impose innovation and focus on geographical expansion paired with operational improvements. They further argue that the value innovators achieve maximum economies of scale and market coverage that their competitors are unable to replicate easily. The case Internet retailer successfully manifested this strategic approach and began a worldwide acquisition of small coupon retailers in 2011.

Nevertheless, competitors will imitate business models and this subsequently engages value innovators in a race to beat the competition. In Malaysia, many coupon retail sites are mushrooming to compete and imitate 
successful companies from foreign markets. Eventually, value innovators may fall into the trap into the vicious cycle of conventional strategic logic and ultimately impede its ability to offer quantum leap in value.

Table 1. Two strategic logics (Kim \& Mauborgne, 2004)

\begin{tabular}{|c|c|c|}
\hline $\begin{array}{l}\text { The Five Dimensions of } \\
\text { Strategy }\end{array}$ & Conventional Logic & Value Innovation Logic \\
\hline Industry assumptions & Industry's conditions are given. & Industry's conditions can be shaped. \\
\hline Strategic focus & $\begin{array}{l}\text { A company should build competitive } \\
\text { advantages. The aim is to beat the } \\
\text { competition. }\end{array}$ & $\begin{array}{l}\text { Competition is not the benchmark. A } \\
\text { company should pursue a quantum leap } \\
\text { in value to dominate the market. }\end{array}$ \\
\hline Customers & $\begin{array}{l}\text { A company should retain and expand } \\
\text { its customer base through further } \\
\text { segmentation and customization. It } \\
\text { should focus on the differences in what } \\
\text { customers value. }\end{array}$ & $\begin{array}{l}\text { A value innovator targets the mass of } \\
\text { buyers and willingly lets some existing } \\
\text { customers go. It focuses on the key } \\
\text { commonalities in what customers value. }\end{array}$ \\
\hline Assets and Capabilities & $\begin{array}{l}\text { A company should leverage its } \\
\text { existing assets and capabilities. }\end{array}$ & $\begin{array}{l}\text { A company must not be constrained by } \\
\text { what it already has. It must ask 'What } \\
\text { would we do if we were starting anew?' }\end{array}$ \\
\hline $\begin{array}{l}\text { Product and } \\
\text { offerings }\end{array}$ & $\begin{array}{l}\text { An industry's traditional boundaries } \\
\text { determine the products and services a } \\
\text { company offers. The goal is to } \\
\text { maximize the value of those offerings. }\end{array}$ & $\begin{array}{l}\text { A value innovator thinks in terms of the } \\
\text { total solution customer seeks, even if } \\
\text { that takes the company beyond its } \\
\text { industry's traditional offerings. }\end{array}$ \\
\hline
\end{tabular}

\subsection{Ripple Effect of Coupon Retailing}

Online coupon retailers have considerably impacted the way local businesses market their products and services. The sales promotional tools are vital marketing mechanisms today for local businesses because are directly impacted by the e-coupon retail industry. Businesses that contract with coupon retailers enjoy business exposure and traffic of new customers. However, the capacity of the firm may suffer overload at such promotional times. On the other hand, businesses that do not contract with coupon retailers must increase marketing efforts tremendously to remain competitive. Hence, industrial players must be able to comprehend how consumers process information received from these coupon retail channels as well as how to position their business in the spur of the "collective buying phenomena". Information on what customers collectively look for can be utilized to effectively market new products or services and fortify the urge for consumers to search and purchase through online coupon retail channels. As consumers perceive information searching as one of the most important features of the Internet (Maignan \& Lukas, 1997) and as better technologies for shopping comparison are being developed (Dickson, 2000), e-coupon retailers may strengthen the relationship between the intention to search for information online and to purchase the goods and services through the Internet platform (Kang et al., 2006). Instead of providing the service of administering detailed product information and comparing product specifications only, an online coupon retail company must advertise ease of use of their services which ultimately results in purchase through these online transaction channels.

A study by Novak, Hoffman and Yung (2000) on online customer experience in purchasing reveals that online search for product information is highly correlated to skill and control. The pragmatic definition of skill refers to an online consumer's capacity for action during the process of navigation and control which pesters the consumer's ability for action (Azjen, 1988). Novak, Hoffman and Yung further argue that the online shopping experience is enhanced through the ease of navigation and interactivity. Having computer skills and necessary devices for attaining facilitates stimulation of e-coupon usage behaviors. By enhancing Internet skill levels, it will support consumers' perceptions of control. Therefore, e-coupon retailers must educate consumers as to how to buy coupons via the Internet. Traditionally, consumers are passive in the process of searching for coupons by waiting for it to show up in newspapers or magazines. Today, consumers are conveniently acquiring e-coupons actively wherever and whenever they want through specialized websites or search engines. In fact, consumers' cost of searching and collecting e-coupons today is significantly lower than traditional coupons (Fortin, 2000). Malaysian coupon retailers are channeling consumer traffic from subscriptions of interested consumers. 
Subscribers will be notified via email whenever coupons are available that match certain product criteria or consumer purchasing patterns.

This study focuses on the market segment of coupon retailing whereby products and services are transacted through online coupon channels. Coupon retailing was introduced to Malaysia in the late 2010 and is mushrooming in the Internet retail segment. International Telecommunications Union (2012) reported that the percentage of Malaysia's population with access to Internet in 2012 was $56.30 \%$. The new mindsets of frugal consumers necessitate coupon-retailing companies to strategize and position their business in ways that consumers perceive most value. This study aims to investigate the various e-value strategies or any underwriting elements embedded in a Malaysian leading e-coupon retail company. The strategies investigated can be categorized into strategic management approaches that are value creation and value innovation from the employee's perspective. The identification of the key factors or strategies enables the development of a comprehensive business model relevant in Malaysia's economic conditions.

Hence, the two research questions for this study are (1) What are the e-value strategies employed by the market leader? and (2) How do e-value strategies provide sustainable competitive advantage through value creation or value innovation? The questions give a chronological order to the content of the research by underlining the key issues to be addressed.

\section{Methodology}

\subsection{A Case Study on a Leading E-Coupon Retail Company in Malaysia}

Preceding the case study's field work, a consent letter and a research brief was sent to the CEO of the case company requesting for permission to conduct interviews in the context of e-value strategies with the managers. The CEO had suggested the appropriate respondents to this study based on their expertise and knowledge on the subject matter. Upon agreement, a literature review is developed to avoid inadvertent repetition, misinterpretation of own data or reinvention of knowledge (Yin, 2009). It goes on to develop an insight towards the erstwhile strategic landscape of Malaysian e-businesses. This case study follows an inductive, descriptive and bottom-up approach where examples from the company are used to develop a broader concept of strategic approach in Malaysia. This case study undertakes the responsibility of not only addressing the e-value strategies of a market leader but also display the current strategic landscape in the e-coupon retail company as Stake calls it "instrumental case study" $(2005,1995)$. To fully understand the strategic thinking behind the market leader in e-coupon retail, adopting the interview method is effective as it is able to highlight a consistent strategy between employees of different teams within the company.

\subsection{Company's Profile}

The case company is a Malaysian start up e-coupon retail company which was acquired by a worldwide market leader at an undisclosed amount in the last few years, initially operated by eight employees and now, it has more than 150 young employees with an average age of 25 years old. Today, this company has close to 1.5 millions of subscribers making it as a leading group buying site in Malaysia. Recently, the case company has expanded to major cities in the country in response to the global growth of the parent company. Their main customers are educated females aged between 25 to 34 years old without children and who usually browse from home.

Founder and CEO of the Malaysian company says that most valuable assets are the people that work for him. Each business function plays a specific role in delivering the overall value for money experience. The coupon retail market leader is a deal-based website that presents the online audience with deep discounts on a product or service offered in Malaysia's major cities. Customers enjoy an array of deals to do, see, eat or buy everyday. The deals are offered for a limited time at deeply discounted prices which cannot be found anywhere else. In return, the businesses are promised a minimum amount of customers. This consumer phenomenon is known as 'collective buying power'. The company prides itself on "honesty, commitment and fun" which guarantees the quality of the deals on the website through transparent information, thorough fact checking, and quirky write-ups.

\subsection{Interviews}

Contextual interviews guided with a semi-structured interview protocol were used to gather rich primary data about the e-value strategies being employed by the market leader and its strategic approach. The interview protocol was designed as an extension of the two research questions to probe rich primary data from the interviewees to ensure that direction of the inquiry was kept focused and a smooth chronological flow of information was established. Precaution to remain on a neutral platform upon inquiry was done through efforts of designing carefully worded, open-ended questions in the interview protocol. The interviewer also asked 
additional questions whenever needed to amplify underlying agendas worth pursuing (Richardson et al., 2005). This had allowed the selected respondents to take charge of the content, to give examples and to expand on the core issues that might invoke deep-seated thoughts. Credibility of interview findings was further validated through recapping efforts at the end of each interview.

In this research, four separate interviews were conducted with the purposive selected respondents. In order to obtain sensitive information from the organization, the respondents were selected based on their authority to access such information and knowledge on the subject matter. Personal interviews with key informants such as the Acting CEO, Head of Operations and representatives from the Mass Communications and Editorial teams were valid, credible and reliable sources of the underlying strategic efforts within a company. The respondents' profiles are given in Table 2 below.

Table 2. Respondents' profiles

\begin{tabular}{|c|c|}
\hline Organizational Position & Profile / Background \\
\hline \multirow{2}{*}{$\begin{array}{l}\text { 1. Acting CEO and Chief } \\
\text { Talent Officer }\end{array}$} & Expertise: People Strategies \\
\hline & Duration of Employment: Since January 2011 (1 year 7 months) \\
\hline \multirow{2}{*}{ 2. Head of Operations } & Expertise: Operational Design and Processes \\
\hline & Duration of Employment: Since February 2011 (1 year 6 months) \\
\hline \multirow{2}{*}{$\begin{array}{l}\text { 3. Representative of Mass } \\
\text { Communication }\end{array}$} & Expertise: Public Relations and Communications \\
\hline & Duration of Employment: Since February 2012 (6 months) \\
\hline 4. Representative & Expertise: Journalism and Editorial \\
\hline Editorial & Duration of Employment: Since April 2011 (1 year 3 months) \\
\hline
\end{tabular}

In order to analyze rich data, Neustaedter (2007) suggests that thoughts and reactions of respondents must be audio recorded to ensure that data from the interview can be transcribed for further analysis. Therefore, the interviews were audiotaped with the respondents' consent and transcribed into a dialogue format by listening to the audio file and documenting the content.

\subsection{Data Analysis Methods}

Holtzblatt et al. (2005) suggests the use of affinity diagramming to categorize data into main themes for easier data interpretation. Using thematic data analysis with the help of an affinity diagram, primary data from key informants of the company understudy were used to find out how the company identifies the key factors that deliver that added value to customers and how the company react to the understanding of implicit and explicit strategic thinking. Rich primary data from the interviews were analyzed and systematically grouped into themes.

\section{Research Findings}

Four main themes on e-value strategies have emerged from this study. They are flexible organizational structure, open communications, innovative spirit, and people focus and strong work culture. Each will be further elaborated in the following sections.

\subsection{Flexible Organizational Structure}

All employees were placed at a level playing field on their daily tasks. Sensitive organizational information such as finance and long-term strategic plans were accessible to all staff in the organization which reflected the inexistence of hierarchy and complete transparency in the company. Performance was measured using key performance indicators regardless of how the tasks were achieved in the flexible work environment. The company utilized cross-functional project teams where each employee works on several projects (deals) at a time. An organic structure supplemented the flow of information throughout the deal creation process. The interdependent core business functions in the deal creation process were managed deal-to-deal by project teams and the tasks were fitted into a streamlined process consisting of members from each department in the deal creation process. Project matrix was used to place employees into projects according to the depth of knowledge and category of deals that the company offers.

The Head of Operations highlighted in the interview that "... a work process flow and structure must be communicated but it must neither impede creativity nor create bureaucracy". The representative of the Editorial 
team agreed that the organization was flat where "... no one in the office is superior to another". The company was not in favour to hierarchies and bureaucracy. Instead, staff were empowered to be responsible and take ownership of their contributions to the organization. According to the Acting CEO, "Power distance only creates barriers and unnecessary formalities". The employees make decisions upon their discretion and take pride in their ability to shape the way the business is done today. Authority was delegated in terms of formulating policy and making decisions to empower the young staff who love the amount of influence they could have in the organization.

\subsection{Open Communication}

In this organization, communication could be two-way between managers and the staff and also lateral amongst the employees. A high level of information flow in top-down communication was fostered using tools like Townhall and intranetwork mail. However, the Head of Operations emphasized that democracy prevailed in decision-making as team leaders who made the final decision would "still run through with the team mates to ensure the logic and validity of the decision." Openness in communication was evident in the company. According to the representative of the Editorial team, “... [Managers] have a monthly check-in to ensure that their [employees] underlying dissatisfaction, suggestions and feedback are heard". According to the Head of Operations, "If our employees have any suggestions of new ways to do things, they can send an informal email to address the issue or even walk over for an ad hoc meeting and suggest solutions to the relevant parties".

Hence pitching new ideas to other departments were also encouraged through various lateral communications. The Acting CEO stressed that communication depends on the comfort level of the individual in choosing the mean of communication. Employees were aware of the on-goings in the organization in the highly transparent lateral communication. The representative of Mass Communications confirmed active lateral communication, “... we make sure that our employees are always up-to-date with the current marketing campaign and strategies. There is a high level of horizontal communication in the office." The company also practised informal verbal motivation to cultivate a positive, nurturing, and supportive culture amongst the employees.

Constructive criticisms were accepted from all sources. In the words of the Acting CEO, “... we really want to hear from the people who are part of the business... So we want to keep all communication portals open." In addition, traditions were created in the company to break down communication barriers, strengthen cross-functional team relationships and foster an overall fun working environment for their people. The company was found to be open to constructive criticism from all sources. They sought feedback from front liners of the company, customers, friends of employees, family members of employees and even non-customers. As the Acting CEO puts it, "We want people to feel that they have influence in the way the business is shaped or the way we do things here". Communication tools like 8-hour clarification window and fire fighting were used in extreme conditions. To avoid misinterpretation of announcements, a follow-up email after each announcement would be sent. This effort could also inform the employees who were not present during the announcement. The Acting CEO related a challenge faced by the company in terms of communication, "I think it is very interesting because when we talk about e-commerce, in general, it is a phenomenon that people in Malaysia are starting to understand and be part of. So when we talk about trust, I think our efforts to build their trust on the company is an ongoing process... We believe with our continuous efforts to promote the trust factor of e-coupon retailer through Facebook and the media enables Malaysia to be eventually one of the top e-coupon retailers." It is noted that e-commerce is a newly introduced phenomenon and it is an iterative process to eliminate consumer's distrust on the brand image through communication.

\subsection{Innovative Spirit}

The company also infused surprises in their work. The element of surprise was seen to resonate in the deals that they offered, in their culture, and in the brand name. The corporate culture of the case company was supportive of embracing uncertainties in e-commerce. This innate quality amongst employees was found to be nurtured as part of the business model as the Acting CEO said, "This desire to surprise is core to how people do their work here". "I think part of what makes it really fun for consumers is this element of discovery, finding new things, being surprised every morning what the deal is. And we try to remain surprising and we try to do things, whether it's the deal you're getting or whether it's the way we're writing about the deal or whether it's the brand and the culture of the company, that's constantly surprising people, because that's kind of the spice of life", said the Representative of Mass Communications.

High level of transparency internally and externally made this e-coupon retailer distinct from its competitors. They designed their business roles around the aspect of providing transparency. For instance, the editorial team had many layers of fact checking to ensure the accuracy, validity, and reliability of information as standards of 
rigor. The practice of full disclosure was also evident in the recruitment process with regards to the transparency levels. "We were offered the clearest description of what to expect, what is expected of me and what a day-to-day scenario in the office is like. There is no hidden agenda." - Representative of Mass Communications.

It is found that creativity was a structured process in the organization. To the Head of Operations, "A structured organization is not synonymous with impeding creativity. It actually facilitates and gives direction to an unanswered question. Structure enables a person, even from a third party, to know who to address questions to. Given a brief highlight of the task roles within each team, the questions will be answered by the most suitable staff as it is the area of their expertise. Creativity is now a structured process in this company; we are a business after all". The staff constantly challenged their current business practices and formulating better ways to do things. They inclined towards unconventional methods to think and solve problems. This is evident in the interview with the Head of Operations, "We love energy, effort, commitment, productivity and most of all, new ideas. This is where the creativity part comes in. As a market leader, we are never afraid to try new things and discover the best way to do something".

The case company propagated a promise that reflected their trust towards the customer's conduct in refunding transactions. The promise reflected a high amount of confidence the business had on the deals they offered. The refund served as a service recovery incentive to make consumers address their dissatisfaction towards them. With such knowledge, they were able to further improve and learn from such experience. In the words of the Mass Communications representative, “... persuading people to believe in a brand is not as impactful as proving to the customers of our transparency and trustworthiness". Their philosophy, "We only sell things that we ourselves want to buy" put the customers as their priority and employees work with a mindset whereby they are the customers in the business as well. Stringent selection of potential merchants also led to better quality deals for the customers. According to the Acting CEO, "We always want to make sure that the experiences that we can afford to provide are great, if not we will not choose to do them."

It is apparent in the interviews that added values were propagated through proof of business conduct in delivering value, supplemented by advanced marketing tools such as microsites, blogs, 'fanatical' customer care and social media communication. According to the Representative of Editorial team, "... we must be creative in offering new value proposition. Shouting out the strengths of the company will not help to build trust on the services but by proving to them with the 'Promise' and transparency would eventually establish a strong, loyal customer base". She added, "Instinctively, in order to survive in a volatile market place, one must perpetually innovate... We think in terms of the total solution customer seeks, even if that takes the company beyond its industry's traditional offering. We cannot accommodate to all consumer needs whether we should offer lower price points or longer deal period - so we make most out of it by trying different approaches and see how consumers react to it. Experimentation of business processes and value proposition is all part of e-commerce and this is how I think we fall under the category of value innovators".

Untapped market opportunities were exploited through insightful ideas on what consumers collectively look for through open communications with the stakeholders. They built upon their core competencies to deliver values such as humor, ease of site navigation and information transparency. They have innovated perpetually and rendered competition as irrelevant by setting the benchmark in the industry. Knowing that not all consumer needs can be satisfied, the company took on a contingency approach of experimentation. The Head of Operations said, "We do not pay much attention to what our competitors are doing because it may impede our creativity in building this company which operates as a startup. We do not want to be imitators but innovators". In other words, they had taken the lead role to shape how e-coupon retail is done in Malaysia. The following interview excerpt with the Head of Operations is vital in indicating the company's strategic efforts of value innovation:

It is a part of business that we do monitor our market share in the industry. However, we do not use them [competitors] as reference to strategize our market position. We believe that the ideas of people in our company are sufficient to create a substantial leap in value that customers seek for. We are constantly measuring our resources and researching methods from business models of other industries to formulate a relevant and comprehensive business plan for this industry. By exploiting opportunities in the market using the right marketing tools and strategy, we are able to stand out from them and remain the stable market leader of the industry.... Because we choose to operate our business like a start up, we all embrace change like we embrace profits, it is something that we look forward to. Sometimes we even look for change to happen to keep things relevant, fresh and fun around the office. We rarely have resistance because we always discuss together and address the importance of why something must be done in this way. So usually they are very positive towards new changes in the organization. 


\subsection{People Focus and Strong Work Culture}

It is found that the people of the organization and the way they do things drove the company's success. The employee's average age was 25 years, similar to the age range of majority of their customers. Hence, they know the buying behaviour of their customers better. The ability to constantly innovate and distinct itself by seeking better ways to do things was evident because the people of the organization were self-sufficiently proactive in the betterment of their work and their work environment. Learning was central to the company as staff were constantly provided with new processes, new roles and new situations for further development of problem solving skills. They were given a sense of ownership and responsibility for their influence on the organization's practices. Team leaders played a role in infusing meaning into their work because the company believed that having a solid reason to do what the employees do would help employees to see their personal development and overall growth in the company. Therefore, employees were aware of the importance of their participation in improving work processes towards their own personal development.

Expectations were clearly benchmarked during induction of new hires. All employees were made aware of the ideal work conduct in the organization through stringent selection in the hiring process. Zany, dedicated, ambitious, self-sufficient high achievers were the commonly shared attitudes among the employees. The Representative of Mass Communications team shared that, "We are clearly aware of our contributions to the company as a whole and having vision to deliver only quality services. It gives us that ongoing commitment which sets us apart from the competitors." In hiring new employees, the Action CEO stressed, "For a company that has strong culture and embraces change, it is not wrong if the person is very rigid and structured. There are many other good organizations that the person would excel in. We need people who can resonate the culture here and I guess stringent recruitment is key to getting the right people to do the right job". The company used unconventional methods to get the right people to do the right job. They must embrace, individuality, spontaneity and the passion for experimentation of individuals that resonate with the culture. More importantly, people were hired not only based on their qualifications but also the 'right attitude' that would synergize the talent pool and to function as a unit. Again, the Acting CEO stressed that the recruitment process ensures that the ideal culture in the company remains dominant.

From the interviews, employees were empowered to make decisions and solve problems in their expertise area that they are responsible for and their personal understanding as a customer of the company. However, discussions among members in a project matrix structure were also found to allow more diverse perspectives in order to arrive at the best solution. Evidently, the company has adopted a contingent decision making approach with regards to the seriousness of the issue. The Editorial team's representative revealed, "We are given authority to make decisions on our own in the company but will require an informal, ad hoc discussion before collective decision making if the severity of the issue and the urgency is outside our area of expertise". She added, "There are some policies or procedures that are compulsory to be implemented because it helps the company to grow and move forward as a single unit. But there are some which are kept optional because essentially, the team here manages the company in Malaysia ... the operational implementation of new processes are fundamentally decided by the local management team in terms of suitability, functionality as well as resources".

\section{Discussions and Conclusion}

The data from the study revealed that the market leading e-coupon retailer embraced experimentation of unconventional thinking in everything they do. Using Kim and Mauborgne's (2004) value innovation logic, the case company operated its business according to the total customer solution customer, even if it meant changing the industry's traditional offerings. Besides that, they fostered a strong work culture that engages the employees in a proactive manner for the betterment of the company as a whole. The decentralized management in the company was supportive of the organization-wide learning process through seeking eccentric ways to innovative change. Our data also suggest that employees of the company self-sufficiently seek for new ways to infuse relevance, freshness and fun into their jobs. The stringent hiring process had ensured resonance of culture and also to get the right person to do the right job. Consumers have now shifted from being passive to active in searching for and obtaining coupons (Fortin, 2000), thus, the deal creation process should inculcate with rigorous fact-checking tasks as conducted by the case company. Only then, customers are assured with accurate and reliable information provided in the e-coupon retailer's website.

The open communication portals enable the company to understand the business from multiple perspectives and get feedback to formulate solid, visionary and long term strategic plans. However, the company must have the ability of adapting to change, which in this case, make the company sustainable in maintaining its market 
position as a leader by anticipating, embracing and perpetually seeking ways to innovative change. The case company was able to pursue a quantum leap in value that they dominate in to sustain its position in the market by building upon their core competencies such as quirky write-ups, thorough fact checking, high-achieving employees, and value proposition delivery of "Our Promise". All these are possible due to the employees are of the same age group of their customers. They work from a perspective where the products, services, and merchants are exactly what customers are looking for. Another competitive advantage factor of this case company is the employee's innate passion for innovation, which in return brings about sustainability in the industry. They engage in surprising, learning, adapting and changing according the dynamism of the consumer demand where functional strategy is used for employees to formulate their own rationalities of action. Essentially, it is to know what is to be achieved, plan how and who to do it, evaluate the progress made and reward or coach positive behaviour. They are also aware of the need to plan with vision in order to think as customers for customers. The combination of the unique attitudes in the talent pool is key to further develop the propositioned values and move the company in the same sustainable, strategic direction. Value innovators achieve maximum economies of scale and market coverage, which their competitors are unable to replicate easily. Therefore, e-value strategy of thorough fact checking is also a strong value proposition guarantee to build customer's trust on the e-coupon retailer's brand image in this infant industry. The case company perpetually encourages employees to nurture their innovative spirit because survival of this company in a volatile e-commerce marketplace is contingent on its ability to innovate and adapt to fast-paced changes. With the innovative spirit, the company the contingency theory approach in decision-making and visionary planning in strategy formulation.

In conclusion, the new mindset of frugal consumers necessitates e-coupon retailing companies to strategize and position their business in ways that consumers perceive most value. The findings of this study give a critical insight of how the case company thinks consumers perceive their business and what are the internal efforts to change consumers' skepticism. The sustainable e-value strategies that emphasize on value innovation employed by the case company which include flexible organizational structure, open communications, innovative spirit, and people focus and strong work culture have advanced the company in the competitive marketplace of the Internet driven industry.

\section{References}

Azjen, I. (1988). Attitudes, Personality and Behaviour. Dorsey Press, Chicago, Illinois.

Barney, J. B. (1991). Firm resources and sustained competitive advantage. Journal of Management, 17, 99-120. http://dx.doi.org/10.1177/014920639101700108

Chua, A. P. H., Khatibi, A., \& Ismail, H. B. (2006). E-Commerce: a study on online shopping in Malaysia. Journal of Social Sciences, 13(3), 231-242.

Datamonitor. (2009). Internet \& Catalog Retail Industry Profile: Global. Internet \& Catalog Retail Industry Profile: Global, 1.

Dickson, P. R. (2000). Understanding the trade winds: The global evolution of production, consumption, and the Internet. Journal of Consumer Research, 27, 115-122. http://dx.doi.org/10.1086/314313

Dyer, J., \& Singh, H. (1998). The relational view: cooperative strategy and sources of interorganizational competitive advantage. Academy of Management Review, 23, 660-679.

Euromonitor. (2011). New Global Report: Internet Retailing Blazing Growth Path. Global Briefing. Retrieved from http://www.portal.euromonitor.com

Euromonitor. (2012a). Internet Retailing in Malaysia. Category Briefing. Retrieved from http://www.portal.euromonitor.com

Euromonitor. (2012b). Consumer Buying Behaviour in the Recession: Global Online Survey. Strategy Briefing. Retrieved from http://www.portal.euromonitor.com

Evans, R., \& Wurster, T. S. (2000). Blown to Bits. Harvard Business School Press, Boston, Massachusetts.

Fortin, D. R. (2000). Clipping coupons in cyberspace: A proposed model of behavior for deal-prone consumers. $\begin{array}{llllll}\text { Journal of Psychology } \& \text { Marketing, } & 17(6), & \text { 515-534. }\end{array}$ http://dx.doi.org/10.1002/(SICI)1520-6793(200006)17:6<515::AID-MAR5>3.0.CO;2-B

Harrison, J. S., \& John, C. H. (1998). Strategic Management of Organizations and Stakeholders: Concepts and Cases. South-Western College Publishing, Cincinnati, Ohio.

Hempel, J. (2010). Social Media Meets Retailing. Fortune, 161(4), 30.

Holtzblatt, K., Wendell, J., \& Wood, S. (2005). Rapid Contextual Design: A How-To Guide to Key Techniques for User-Centered Design. Morgan Kaufmann. 
Hooft, F. V., \& Stegwee, R. (2001). E-business strategy: how to benefit from a hype. Logistics Information Management, 14(1/2), 44-53. http://dx.doi.org/10.1108/09576050110360223

Huizingh, E. K. R. E. (2002). Towards successful e-business strategies: a hierarchy of three management models. Journal of Marketing Management, 18(7/8), 721-747. http://dx.doi.org/10.1362/0267257022780615

International Telecommunications Union. (2012). Percentage of individuals using the Internet, fixed (wired) Internet Subscriptions, fixed (wired) broadband subscriptions. Retrieved from http://www.itu.int/ITU-D/icteye/Reporting/ShowReportFrame.aspx?ReportName=/WTI/InformationTechno logyPublic\&ReportFormat $=$ HTML4.0\&RP_intYear=2010\&RP_intLanguageID=1\&RP_bitLiveData=False

Kang, H., Hahn, M., Fortin, D., Hyun, Y., \& Eom, Y. (2006). Effects of perceived behavioral control on the consumer usage intention of e-coupons. Psychology \& Marketing, 23(10), 841-864. http://dx.doi.org/10.1002/mar.20136

Kim, W. C., \& Mauborgne, R. (1999). Strategy, Value Innovation and the Knowledge Economy. Sloan Management Review (Spring 1999), 41-53.

Kim, W. C., \& Mauborgne, R. (2004). Value Innovation. Harvard Business Review, 82(7/8), 172-180.

Maignan, I., \& Lukas, B. A. (1997). The nature and social uses of the Internet: A qualitative investigation. Journal of Consumer Affairs, 31(2), 346-371. http://dx.doi.org/10.1111/j.1745-6606.1997.tb00395.x

Moore, K., \& Ruddle, K. (2000). Organizing for E-business. In C. Sauer \& L. Willcocks (Eds.), Moving to E-business (pp. 99-123). Random House, London.

Neustaedter, C. (2007). Domestic Awareness and Family Calendars: PhD Dissertation. University of Calgary, Canada.

Novak, T. P., Hoffman, D. L., \& Yung, Y. F. (2000). Measuring the Customer Experience in Online Environments: A Structural Modelling Approach. Marketing Science, 19(1). Special Issue on Marketing Science and the Internet (Winter, 2000), 22-42.

Porter, M. E. (1985). Competitive Advantage: Creating and Sustaining Superior Performance. Free Press, New York.

Porter, M. E. (2001, Marth). Strategy and the Internet. Harvard Business Review, 63-78.

Rajagopalan, N., \& Spreitzer, G. M. (1996). Toward a theory of strategic change: a multi-lens perspective and integrative framework. The Academy of Management Review, 22(1), 48-79.

Raupp, J., \& Hoffjann, O. (2012). Understanding strategy in communication management. Journal of Communication Management, 16(2), 146-161. http://dx.doi.org/10.1108/13632541211217579

Reynolds, J. (2000). Organising for e-business - the case of Kingfisher. European Retail Digest, 27, 49-51.

Richardson, C., Faulkner, G., McDevitt, J., Skrinar, G., Hutchinson, D., \& Piette, J. (2005). Integrating physical activity into mental health services for individuals with serious mental illness. Psychiatric Services, 56, 324-331. http://dx.doi.org/10.1176/appi.ps.56.3.324

Stake, R. E. (1995). The art of case study research. Thousand Oaks, Sage Publications, California.

Stake, R. E. (2005). Qualitative case studies. In N. K. Denzin \& Y. A. Lincoln (Eds.), The Sage handbook of qualitative research. Thousand Oaks, Sage Publications, California.

Steinmann, H., \& Schreyögg, G. (2005). Management. Grundlagen der Unternehmensführung. Konzepte-Funktionen-Fallstudien (6th ed.). Gabler, Wiesbaden.

Steyn, B. (2003). From strategy to corporate communication strategy: a conceptualization. Journal of Communication Management, 8(2), 168-83. http://dx.doi.org/10.1108/13632540410807637

Thompson, L. (2000). E-commerce: changing the rules of strategy implementation. Strategy \& Leadership, 28(4).

Tourish, D., \& Hargie, C. (1996). Internal communication: key steps in evaluating and improving performance. Corporate Communications: An International Journal, 1(3), 11-16. http://dx.doi.org/10.1108/eb059593

Whittaker, C. (1996). Integrated communication: a theoretical perspective. Corporate Communications: An International Journal, 1(3), 17-21. http://dx.doi.org/10.1108/eb059594

Yin, R. K. (2009). Qualitative Research from Start to Finish. The Guilford Press, New York.

\section{Copyrights}

Copyright for this article is retained by the author(s), with first publication rights granted to the journal.

This is an open-access article distributed under the terms and conditions of the Creative Commons Attribution license (http://creativecommons.org/licenses/by/3.0/). 